"This accepted author manuscript is copyrighted and published by Elsevier. It is posted here by agreement between Elsevier and MTA. The definitive version of the text was subsequently published in Immunology Letters, 160 (2), 2014 Feb 1, DOI: 10.1016/j.imlet.2014.01.014. Available under license CC-BY-NC-ND."

\title{
Autoantibodies to complement components in C3 glomerulopathy and atypical
} hemolytic uremic syndrome

Mihály Józsi ${ }^{\mathrm{a}}$, Stefanie Reuter ${ }^{\mathrm{b}}$, Pilar Nozal ${ }^{\mathrm{c}}$, Margarita López-Trascasa ${ }^{\mathrm{c}, \mathrm{d}}$, Pilar SánchezCorral $^{\text {d,e }}$, Zoltán Prohászka ${ }^{\mathrm{f}}$, Barbara Uzonyi ${ }^{\mathrm{g}}$

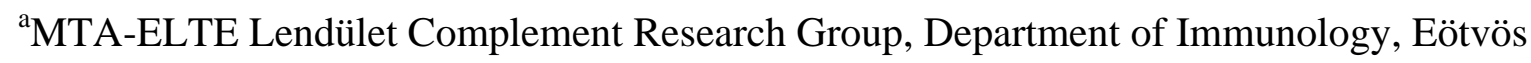
Loránd University, Budapest, Hungary; ' Junior Research Group for Cellular Immunobiology, Leibniz Institute for Natural Product Research and Infection Biology, Jena, Germany; ${ }^{\mathrm{c}}$ Unidad de Inmunología, Hospital Universitario La Paz, IdiPAZ, Madrid, Spain; ${ }^{\mathrm{d}}$ CIBERER U754, Madrid, Spain; ' Unidad de Investigación, Hospital Universitario La Paz, IdiPAZ, Madrid, Spain; ${ }^{\mathrm{f}}$ Research Laboratory, 3rd Department of Internal Medicine, Semmelweis

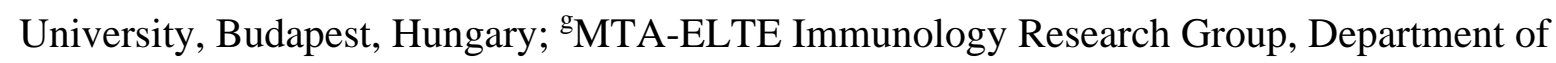
Immunology, Eötvös Loránd University, Budapest, Hungary

\section{Corresponding author:}

Dr. Mihály Józsi, MTA-ELTE Lendület Complement Research Group, Department of Immunology, Eötvös Loránd University, Pázmány Péter s. 1/c, 1117 Budapest, Hungary. Phone: +36 1 3812175. Fax: +36 1 3812176. E-mail: mihaly.jozsi@gmx.net 


\begin{abstract}
The alternative pathway of complement is implicated in the pathogenesis of several renal diseases, such as atypical hemolytic uremic syndrome, dense deposit disease and other forms of C3 glomerulopathy. The underlying complement defects include genetic and/or acquired factors, the latter in the form of autoantibodies. Because the autoimmune forms require a specific treatment, in part different from that of the genetic forms, it is important to detect the autoantibodies as soon as possible and understand their characteristics. In this overview, we summarize the types of anti-complement autoantibodies detected in such diseases, i.e. autoantibodies to factor $\mathrm{H}$, factor I, C3b, factor B and those against the C3 convertases (C3 nephritic factor and C4 nephritic factor). We draw attention to newly described autoantibodies and their characteristics, and highlight similarities and differences in the autoimmune forms of these diseases.
\end{abstract}

\title{
Keywords
}

autoantibodies; kidney disease; atypical hemolytic uremic syndrome; C3 glomerulopathy; complement regulation; C3 convertase; factor B; factor $\mathrm{H}$; C3 nephritic factor 


\section{Introduction}

The complement system is one of the most powerful effector systems of innate immunity, providing protection against infections, participating in the clearance of immune complexes and cellular debris and influencing the adaptive immune response [1]. While it can effectively destroy microorganisms, a strict regulation ensures that complement does not harm host cells and tissues. Imbalance between complement activation and inhibition can lead to various diseases [2]. Genetic defects in complement components may manifest as complement deficiency or as altered function. In addition, acquired complement abnormalities due to autoantibodies against specific components are associated with several diseases, including kidney diseases such as C3 glomerulopathy, membranoproliferative glomerulonephritis $(\mathrm{MPGN})^{1}$ and atypical hemolytic uremic syndrome (aHUS).

\subsection{Complement activation and inhibition}

Complement can be activated via three major pathways, the alternative, the classical and the lectin pathways [1] (Fig. 1). The alternative pathway is continuously and spontaneously activated by the hydrolysis of the tioester bond in the central component C3. The resulting $\mathrm{C} 3\left(\mathrm{H}_{2} \mathrm{O}\right)$ (also termed iC3) has „C3b-like” properties by acquiring the ability to bind to complement receptor type 1 (CR1, CD35), as well as to factor B. Factor D cleaves the $\mathrm{C} 3\left(\mathrm{H}_{2} \mathrm{O}\right)$-bound factor $\mathrm{B}$, which leads to the formation of the initial $\mathrm{C} 3\left(\mathrm{H}_{2} \mathrm{O}\right) \mathrm{Bb} \mathrm{C} 3$ convertase enzyme of the alternative pathway that cleaves C3 into C3a and C3b. C3b forms additional convertases (C3bBb) which generate more C3b. The classical pathway is activated by target-bound immunoglobulins or pentraxins, which bind C1q and initiate the cascade. The lectin pathway is activated by target-bound mannan-binding lectin or ficolins. Activation of both the classical and the lectin pathways result in the generation of the classical/lectin pathway C3 convertase enzyme (C4bC2b), which cleaves C3 into C3a and C3b. Because C3b 
feeds into the alternative pathway, the latter also represents a powerful „amplification loop” of the classical/lectin pathways. Thus, the three pathways lead to the generation of C3 convertases and converge in the cleavage of the central complement component C3 into C3a and C3b, which is a critical step in complement activation and generation of opsonic molecules.

The C3 convertases, when binding an additional C3b molecule, form the C5 convertases (C3bBbC3b for the alternative pathway, and C4bC2bC3b for the classical/lectin pathway), which cleave C5 into C5a and C5b and thus initiate activation of the terminal pathway. The terminal pathway incorporates components C6 to C9, thus leading to the formation of terminal complement complexes (TCC or C5b-9), also called membrane attack complexes at cell surfaces and SC5b-9 when in solution bound to S protein (Fig. 1).

Because of the central role of C3 and the C3 convertases in complement activation, it is not surprising that there is an array of regulatory molecules acting on C3 or the convertases. The spontaneous decay of C3 convertases can be accelerated by the membrane-bound proteins CR1 and decay accelerating factor (DAF, CD55), and the soluble regulators factor $\mathrm{H}$ (for the alternative pathway C3 convertase) and C4b-binding protein (for the classical/lectin pathway convertase). The only positive regulator is the plasma protein properdin, which extends the half-life of the $\mathrm{C} 3 \mathrm{bBb}$ convertase. In addition, the complement regulator factor I is a serine protease that specifically cleaves and thus inactivates the C3b and C4b molecules in the presence of a cofactor. For C3b inactivation, factor I requires factor H, CR1 or membrane cofactor protein (MCP, CD46) as a cofactor. C4b inactivation by factor I proceeds in the presence of C4b-binding protein, MCP or CR1.

Maintaining the delicate balance between complement activation and inhibiton is important under physiological conditions. Misdirected or exaggerated complement activation (e.g., due to overactivation or defective regulation) may cause various diseases [2,3]. In this 
context, genetic alterations and/or autoantibodies to complement components are implicated in a growing number of diseases [4]. In the present review, we focus on the role of anticomplement autoantibodies in the kidney diseases C3 glomerulopathies, particularly dense deposit disease (DDD), and aHUS. The common underlying pathomechanism of these renal diseases involves the complement system, and because often similar mutations or autoantibodies are detected in many patients, it was suggested that there is a disease spectrum of related disorders and the underlying defects manifest as different disease entities $[5,6]$. Here, we summarize the biological features and clinical characteristics of anti-complement autoantibodies and discuss similarities and differences in the autoimmune forms of C3 glomerulopathies and aHUS.

\section{Autoantibodies in C3 glomerulopathy}

C3 glomerulopathy is characterized predominantly by C3 deposition in the glomeruli, usually in the absence of IgG, and complement activation due to dysregulation of the alternative pathway $[7,8]$. Several disease entities fall under the umbrella of C3 glomerulopathy, such as DDD (also termed MPGN II), CFHR5 nephropathy and C3 glomerulonephritis [8].

While anti-C1q antibodies have been described in patients with glomeulonephritis [911], most known anti-complement autoantibodies in patients with C3 glomerulopathy target the C3 convertases (C3 and C4 nephritic factors, anti-factor $\mathrm{B}$, anti-C3b) or factor $\mathrm{H}$ (antifactor $\mathrm{H})$, a regulator of the alternative pathway C3 convertase.

\subsection{C3 nephritic factor}

The most common anti-complement autoantibodies reported in patients with C3 glomerulopathy target the alternative pathway C3 convertase C3bBb. Regarding their epitope specificity, isotype and effect on the convertase, these C3 nephritic factors (C3Nefs) form a 
heterogeneous group of autoantibodies with the common feature of preventing the dissociation of $\mathrm{Bb}$ from the convertase and thus prolonging the half-life of the convertase.

C3Nefs are IgG or IgM antibodies that bind to the C3bBb convertase [12,13]. Most C3Nefs recognize a neoepitope on the $\mathrm{C} 3 \mathrm{bBb}$ complex, but some of them are able to bind C3b or Bb alone [14]. Some C3Nefs require the presence of properdin, others are properdinindependent [15,16]. All C3Nefs prevent the natural intrinsic decay of C3bBb [14,17], but the stabilized convertases are variously resistant against extrinsic decay mediated by factor $\mathrm{H}$, CR1 or DAF [18-22]. Stabilization of the C3bBb convertase by C3Nef results in higher and prolonged activity, C3 and C5 consumption and activation of the terminal pathway [16,17]. However, certain C3Nefs were reported to inhibit C5 cleavage [23]. This functional heterogeneity is clearly mirrored in the studies and case reports. C3Nef has been detected in $\sim 50 \%$ in the cases of MPGN I and MPGN III, and in up to $80 \%$ of MPGN II/DDD patients $[10,24,25]$. Despite the strong association of C3Nef with MPGN, there is uncertainty regarding the nephritogenic role of C3Nef. Some studies support the correlation between C3Nef and disease course or complement status, while others found no evidence in this regard [26]. Furthermore, C3Nef is not exclusively associated with MPGN, its presence has been reported in patients with C3 glomerulonephritis without MPGN, partial lipodystrophy, poststreptococcal glomerulonephritis, systemic lupus erythematosus (SLE), meningococcal meningitis and also in healthy individuals [27-32].

Consensus for the detection and characterization of C3Nefs is also lacking. The few laboratories routinely measuring C3Nef use different methods, predominantly hemolytic assays, and occassionally ELISA and surface plasmon resonance assay that detect various groups of C3Nefs [22,33-37]. Results of the various measurements can also be influenced by the presence of $\mathrm{C} 4$ nephritic factor (C4Nef), anti-C1q autoantibodies or mutations in factor $\mathrm{H}$ 
or factor I [10,38-40]. Recent data suggest that a combination of different assays are likely to identify most C3Nefs, including occult cases [11,22,37].

The heterogeneity of C3Nefs in appearance and function and the difficulties in their detection and characterization led to some confusion in the literature, and leaves open the question, whether C3Nef is the primary cause of the disease or it emerges secondarily as a consequence of the prolonged existence of the convertase neoepitopes. DDD patients with C3Nef often present with hypocomplementemia [25], and C3- and/or C5 activation fragments can be observed in the glomerular deposits [41]. Thus, the presence of C3Nef can alter the disease course by promoting and adding to the enhanced complement activation. Further studies and characterization of individual C3Nefs could help understanding its role in disease pathogenesis in more detail.

\subsection{C4 nephritic factor}

Antibodies recognizing the classical pathway C3 convertase C4bC2b have been described and termed C4Nefs. C4Nefs are IgG autoantibodies that were first reported in a patient with postinfectious glomerulonephritis [42] and in patients with SLE [43]. Binding of C4Nef to the C4bC2b convertase prolongs the half-life of the convertase, preventing both the intrinsic and the C4b-binding protein-, CR1- or DAF-mediated extrinsic decay [19,44,45]. Stabilization of the C4bC2b convertase by C4Nef leads to enhanced C3 and C5 cleavage. C4Nef also protects the C4b fragment against cleavage by factor I [44]. C4Nef isolated from a patient with chronic glomerulonephritis was shown to bind to a neoepitope of the C4bC2b convertase [46], similar to the C4Nef analyzed by Gigli et al., that only inhibited C4b cleavage when it was in complex with C2b [44]. Presence of C4Nef was detected both alone and together with C3Nef in patients with glomerulonephritis [38,39]. Although the only study analyzing a cohort of 100 hypocomplementemic MPGN patients reported a frequency of 20\% for C4Nef alone or 
together with C3Nef [39], screening for C4Nef is currently not part of the routine diagnostics. C4Nef can be measured by hemolytic assay or ELISA [39,47]. Problems with the specificity and reliability of the assay are similar to the C3Nef assay, as discussed above. It is unclear at present if C4Nefs are common and if they are relevant to disease. Therefore, it would be worthwhile to clarify the frequency and relevance of C4Nef.

\subsection{Factor $B$ and $C 3 b$ autoantibodies}

Autoantibodies targeting the individual components of the C3bBb convertase, $\mathrm{C} 3 \mathrm{~b}$ and factor $\mathrm{B}$, in glomerulonephritis patients were also described. At present, one patient with factor B autoantibody and two patients with combined factor B and C3b autoantibodies have been described in detail $[11,48]$. The factor B autoantibody, identified by ELISA in a DDD patient who was negative for C3Nef (as measured by the traditional hemolytic assay), bound both to native factor $\mathrm{B}$ in serum and to $\mathrm{Bb}$ in the solid-phase $\mathrm{C} 3 \mathrm{bBb}$ convertase [11]. Thorough functional characterization of the factor B autoantibody revealed stabilization of the $\mathrm{C} 3 \mathrm{bBb}$ convertase against both intrinsic and factor $\mathrm{H}$-mediated decay, resulting in enhanced $\mathrm{C} 3$ cleavage and activation of the alternative pathway. However, in contrast to most C3Nefs, this factor B antibody inhibited formation of the C5 convertase and terminal pathway activation [11]. The other two factor B autoantibodies described also recognized the whole factor B and the purified IgG increased $\mathrm{Ba}$ production [48]. The C3b antibodies were not further characterized.

As in the case of C3Nefs and C4Nefs, there is no proof that these factor B autontibodies are cause of the disease; rather, they may appear secondarily due to the increased amounts of complement cleavage products in the plasma. Such a notion is supported by further analysis of the anti-factor B positive patient's sample [11], indicating appearance of antibodies against several components of the C3bBb convertase, such as factor 
B, C3b and properdin, although the factor B autoantibody is dominant (Fig. 2). In addition to these cases, Zhang et al. described factor B autoantibodies presenting together with C3Nef in three patients, but the antibodies were not characterized [37].

\subsection{Factor $\mathrm{H}$ autoantibodies}

The first factor $\mathrm{H}$ autoantibody described was a „mini-autoantibody” consisting of lambda light chain dimers, detected in a patient with membranoproliferative glomerulonephritis [49]. This mini-autoantibody caused uncontrolled complement activation and C3 consumption when added to normal human serum via inhibiting factor H. Later, the binding site of this antibody was shown to be in domain 3 of factor $\mathrm{H}$, i.e., in the $\mathrm{N}$-terminal part of the molecule responsible for complement regulatory function (short consensus repeat [SCR] domains 1-4) [50].

Only very recently a few additional patients with factor $\mathrm{H}$ autoantibodies have been reported. One patient diagnosed with DDD had monoclonal gammopathy and autoantibodies against factor $\mathrm{H}$ and plasminogen [51]. The binding site of this autoantibody was in the $\mathrm{N}$ terminal complement regulatory domains of factor $\mathrm{H}$ and the isolated IgG fraction of the patient inhibited fluid-phase cofactor activity of factor $\mathrm{H}$ [51]. Interestingly, the antibody also bound to factor H-like protein 1 (CFHL1) [51], which is a splice variant derived from the CFH gene, and consists of the $7 \mathrm{~N}$-terminal domains of factor $\mathrm{H}$ and a unique four aminoacid long tail. CFHL1 thus shares complement regulatory function with factor H. Analysis of the IgG fraction isolated from the patient showed that most autoantibody molecules were in fact bound to CFHL1 (Fig. 3). Although not tested, these autoantibodies are expected to inhibit the cofactor activity of CFHL1 as well. The relative contribution of factor H and CFHL1 to local or systemic complement inhibition is unclear, but this case suggests that CFHL1 deserves more attention as it could influence renal pathology. 
Goodship et al. screened 16 patients with MPGN, of whom two patients were strongly positive for factor $\mathrm{H}$ autoantibodies [52]. One patient had MPGN type I without C3Nef, while the second patient had DDD and was positive for C3Nef. Both factor $\mathrm{H}$ autoantibodies bound predominantly to the N-terminal domains of factor H (SCRs 1-5) and in the second patient also to SCRs 8-15. IgG isolated from both patients increased alternative pathway mediated hemolysis of rabbit erythrocytes [52]. Both patients had two copies of CFHR1 and CFHR3.

One patient diagnosed with glomerulonephritis with isolated C3 deposits and a low titer of factor $\mathrm{H}$ antibodies has also been reported, but the antibody was not characterized in detail [53]. In a recent study, a cohort of 32 patients with DDD was analyzed and one patient was found positive for factor $\mathrm{H}$ autoantibodies [37]. Binding sites of the autoantibodies have not been determined and functional analyses have not been performed.

In summary, patients with glomerulonephritis should be screened for the presence of circulating factor $\mathrm{H}$ autoantibodies. The frequency of such antibodies - based on the current available literature - is markedly lower than that seen in aHUS (see below); however, systematic testing of patients should be performed to establish the frequency of these antibodies. To date, all four analyzed antibodies impaired the complement inhibitory function of factor $\mathrm{H}$ by binding to the complement regulatory domains (SCRs 1-5). Notably, two out of the four well-characterized factor $\mathrm{H}$ autoantibodies were monoclonal [49,51]. In a recent study, 10 of 32 patients with C3 glomerulonephritis had evidence of monoclonal gammopathy associated with complement activation and the authors suggested that monoclonal immunoglobulins acted as autoantibodies to complement-regulatory proteins [54]. This potential association should be investigated in the future.

\section{Autoantibodies in aHUS}


The complement system is clearly involved in the disease pathomechanism in the majority of aHUS patients. Disease-associated polymorphisms, risk haplotypes and mutations in factor $\mathrm{H}$, factor I, MCP, C3, factor B, thrombomodulin, and clusterin have been described [55]. Genomic rearrangements in the factor $\mathrm{H}$ gene cluster that affect the factor $\mathrm{H}$ gene $(\mathrm{CFH})$ and/or some of the adjacent genes coding for factor H-related proteins (CFHR) are also known [55,56]. In addition to the genetic predisposing factors, acquired, autoimmune forms of aHUS are relatively frequent. Approximately 6-11\% of aHUS patients have circulating anti-factor $\mathrm{H}$ antibodies [57] and 3 cases of factor I autoantibodies were reported recently [58].

\subsection{Factor $H$ autoantibodies}

Factor $\mathrm{H}$ autoantibodies were first reported in three children with aHUS [57] and have been described since then in many other aHUS patients. The autoantibodies are detected by ELISA that uses purified factor $\mathrm{H}$ and allows determination of antibody titers and follow-up of titer changes in response to treatment. Our own experiments as well as a recently published comparison of various test methods support the originally described factor $\mathrm{H}$ autoantibody ELISA as a robust and well reproducible assay [59-61]. Some patients have IgA class autoantibodies in addition to IgG [62]. Because the standard anti-factor H ELISA only measures free antibodies, a few studies investigated the factor H-IgG complexes in patient samples [62-65]. The results showed that in some patients with seemingly low antibody titer the majority of autoantibodies are in complex with factor $\mathrm{H}$. The amount of complexes actually shows better correlation with the disease course than that of the free autoantibodies [64]. It is important to note that the autoantibodies may interfere with the measurement of factor $\mathrm{H}$ serum levels, depending on the antibodies used in the factor $\mathrm{H}$ ELISA, due to overlapping binding sites [61-63,66]. 
Clinical features of factor H-autoantibody associated aHUS have been described [64]. Most patients are children, but a few adults are also reported. Interestingly, a recent report described Indian aHUS patients [67] among which the frequency of the autoantibodies is much higher (56\%) than the previously reported 6-11\% in three aHUS cohorts $[57,68,69]$ and $25 \%$ in a pediatric aHUS cohort [70], indicating that population differences in genetic and/or environmental predisposing factors play important roles.

The overwhelming majority of factor $\mathrm{H}$ autoantibody positive aHUS patients present with the homozygous deletion of the CFHR1 gene, which in most cases is deleted together with CFHR3 due to non-allelic homologous recombination [67-72]. In a few patients other genomic alterations are identified, such as CFHR1 deletion together with CFHR4 deletion, or combined CFHR3-CFHR1 and CFHR1-CFHR4 deletions [69,72]. Factor H autoantibodies can also be associated with mutations in CFHR1, factor H, C3, MCP or factor I [69,72]. The strong association between the lack of CFHR1 and the presence of the factor $\mathrm{H}$ autoantibodies suggests that CFHR1 is required to induce and/or maintain tolerance against factor $\mathrm{H}$. Because the CFHR3-CFHR1 deletion is common in the healthy population, other predisposing genes (such as certain HLA haplotypes) and environmental factors (such as infections) are suspected. The role of infection in the generation of autoantibodies is supported by the generally young age of the patients and because an infection is often observed prior to disease manifestation $[64,67,68]$.

The binding sites of the factor $\mathrm{H}$ autoantibodies were mapped in a few studies. The first investigations demonstrated that the major autoantibody binding site lies in the Cterminal domains of factor $\mathrm{H}$ (particularly SCR20), which are responsible for the binding of factor $\mathrm{H}$ to cell surfaces, thus protecting autologous cells from complement-mediated damage $[68,73]$. This was confirmed recently by other studies $[65,69]$. However, the autoantibodies may bind to other parts of the factor $\mathrm{H}$ molecule, such as SCRs 8-11 [68,69] or even to the 
complement regulatory domains SCRs 1-4 [65,69], as detected in samples collected in the acute phase of the disease [65]. Thus, autoantibodies may bind to various domains and inhibit several functions of factor $\mathrm{H}$.

Most of the described factor $\mathrm{H}$ autoantibodies also recognize CFHR1, due to strong sequence similarity of its C-terminal domains with the homologous domains of factor $\mathrm{H}$. $[62,65,69]$. This fact could be most relevant for understanding why the vast majority of aHUS patients with factor $\mathrm{H}$ autoantibodies is CFHR1-deficient. A recent report also showed crossreactivity with the factor H-related protein CFHR2 [65].

Functional analyses of aHUS-associated autoantibodies demonstrated impaired binding to surface-deposited C3b and host-like surfaces, leading to reduced protection from complement-mediated lysis that is routinely measured by a hemolytic assay using sheep erythrocytes $[62,63,73]$. Autoantibodies may interfere with the cofactor- and convertase decay accelerating activity of factor $\mathrm{H}[57,65]$. In addition, factor $\mathrm{H}$ autoantibodies may impair the interaction of both factor $\mathrm{H}$ and CFHR1 with pentraxin 3 [74]. These data further demonstrate that multiple functions of factor $\mathrm{H}$ could be inhibited by the autoantibodies, but there are differences in this regard among the patients.

Altogether, aHUS-associated factor $\mathrm{H}$ autoantibodies differ from those found in patients with DDD/C3 glomerulopathy. The binding sites (N-terminal in DDD/MPGN and predominantly C-terminal in aHUS) and effects on factor $\mathrm{H}$ functions are different. Moreover, factor $\mathrm{H}$ autoantibodies are strongly associated with CFHR1 deletion in aHUS whereas similar genetic predisposition to the development of factor $\mathrm{H}$ autoantibodies in $\mathrm{C} 3$ glomerulopathy is currently not supported by evidence.

\subsection{Factor I autoantibodies}


In three out of 175 investigated aHUS patients autoantibodies to factor I were detected by ELISA [58]. Both free antibodies and circulating complexes were measured. Functional analysis of available samples demonstrated no significant effect on factor I function, and it is possible that such antibodies are epiphenomena. During our own studies, we have detected factor I antibodies of IgG3 class in two aHUS serum samples. Such antibodies were not detected in controls and the binding to factor I was specific (Fig. 4). The frequency of these autoantibodies in aHUS $(<2 \%)$ is clearly less than that of the factor $\mathrm{H}$ autoantibodies (611\%). The potential pathogenic role and diagnostic utility of the factor I autoantibodies remains unknown.

\subsection{C3b autoantibodies}

When screening patient samples for autoantibodies by ELISA, we use several antigens as controls and to identify possible novel antibodies. In one aHUS patient, specific IgG binding to C3b was found, without the presence of factor $\mathrm{H}$ autoantibodies. When further analyzing this sample, it became apparent that the antibody bound to the C3b and iC3b fragments, but poorly to intact C3 and not to C3d (Fig. 5). It is possible that such antibody is generated due to the sustained complement activation during disease and it may contribute to pathologic complement activation; however, a direct pathogenic role is uncertain.

\section{Treatment options}

In the above mentioned autoimmune kidney diseases pathogenic autoantibodies against complement proteins are therapeutic targets. The aim of the therapy can be neutralization of the pathogenic autoantibodies, replacement of the affected complement components in the acute phase of the disease, as well as the reduction of the titer of autoantibodies with the elimination of antibody producing B cells. Plasma exchanges are often applied in combination 
with immune adsorption and/or immunosuppressive therapy (such as corticosteroids, pulse cyclophosphamide treatment or targeted B cell depletion with rituximab). Available clinical data suggest a good efficacy of plasma exchanges and immunosuppression in factor $\mathrm{H}$ autoantibody-associated aHUS [63,64,67,75-77]. Similarly, factor H-associated DDD was successfully treated [51]. Importantly, the autoantibodies should also be eliminated before kidney transplantation $[48,78,79]$.

The efficacy of eculizumab, a humanized monoclonal antibody directed against C5, was recently demonstrated in patients with complement-mediated aHUS [80] and according to case reports also in some patients with various forms of C3 glomerulopathy [8,81-84]. This drug was successfully used in patients with autoantibody mediated forms of the above diseases [85] pointing towards the importance of terminal pathway activation and generation of inflammation in these diseases [86]. It is important to note that eculizumab inhibits further activation at C5, but the underlying complement activation and C3 consumption is not inhibited by the drug. Thus, other complement inhibitors targeting uncontrolled C3 activation may be useful in the treatment of such diseases.

Purified complement proteins may be considered to increase the level of functionally active, antibody-free factors, such as purified or recombinant factor $H$, to restore physiological complement regulation. In addition to the production of recombinant full-length factor H [87], two recent reports described an engineered „mini-FH” in which domains 5-18 are deleted, thus the protein is reduced to the complement regulatory (SCRs 1-4) and surface recognition (SCRs 19-20) domains. Such recombinant constructs were even more effective than full-length factor $\mathrm{H}$ in inhibiting complement $\mathrm{C} 3$ deposition in vitro on paroxysmal nocturnal hemoglobinuria-erythrocytes [88] and on endothelial cells, as well as inhibiting factor $\mathrm{H}$ autoantibody-induced hemolysis of host-like cells [89]. After further development and optimization, such targeted inhibitors might effectively prevent uncontrolled complement 
activation in the acute phase of disease and help reduce or even prevent complement-mediated damage to the kidney.

\section{Conclusion}

The discussed complement-specific autoantibodies are summarized in Table I.

In C3 glomerulopathy, in addition to the commonly detected C3Nef, rarely other antibodies are identified. The example shown in Fig. 3 demonstrates weak antibody positivity to $\mathrm{C} 3 \mathrm{~b}$ and properdin, in addition to factor $\mathrm{B}$, indicating the presence of autoantibodies to all components of the convertase. Systematic screening of patients and detailed characterization of the individual antibodies are needed to understand their frequency and relevance in the disease.

In aHUS, the importance of factor $\mathrm{H}$ autoantibodies is established, whereas other autoantibodies, such as those against factor I [58] and C3b can occassionally be detected in patients with aHUS, as also shown here (Figs. 4 and 5). The rare cases of factor I and C3b autoantibodies with unknown significance, as well as false positive results for factor $\mathrm{H}$ autoantibodies [59,61] suggest that caution should be taken in the interpretation of ELISA results and, particularly, before commencing perhaps unnecessary immunosuppressive treatment.

In summary, factor $\mathrm{H}$ autoantibodies are targeted against different epitopes in $\mathrm{C} 3$ glomerulopathy/DDD and aHUS. Autoantibodies to factor I and C3b are rare and their functional relevance is yet unclear. Autoantibodies to the C3 convertase or its components are common in C3 glomerulopathy, but may be secondary phenomena due to the increased amounts of complement activation products in the patients. Because of the convertase stabilization effect of these autoantibodies, it is important to be aware of their presence. 
It is vital to identify the autoantibodies as soon as possible because timely and targeted therapy increases the chance of successful treatment. The pathogenic factor $\mathrm{H}$ autoantibodies can be quickly (within 24-48 hours) and easily detected by ELISA and the antibody titers can be monitored during disease course by this inexpensive and robust method. It is recommended to screen aHUS and C3 glomerulopathy patients for factor $\mathrm{H}$ autoantibodies in a timely manner, regardless of the suspicion for possible genetic risk factors in the patients. The relevance of positivity for anti-factor I, anti-C3b or anti-properdin antibodies is unclear at the moment because of the limited data, the relatively low titers in the reported cases and uncertainty of functional effects and pathogenicity of the antibodies. Whereas the direct pathogenic role of $\mathrm{C} 3 \mathrm{Nef}$ is not clear and C3Nef is more difficult to detect due to the antigenic and functional heterogeneity of these autoantibodies, it is recommended to apply a combination of tests for the identification of C3Nef, which if positive, corroborates the disease diagnosis and may be helpful in choosing therapy (such as complement inhibition) and monitoring response to treatment. Similarly, detection of factor B autoantibodies is easily done by ELISA and a positive result confirms the role of alternative complement pathway.

With eculizumab available and novel complement inhibitors in the development pipeline, new, emerging options for treatment could be considered and tried in the future, possibly allowing tailored therapy. The successful treatment may include inhibition of complement activation and replacement of dysfunctional proteins, removal of immune complexes and attempts to eliminate autoantibody producing cells. 


\title{
6. Acknowledgements
}

M.J. was supported by the Deutsche Forschungsgemeinschaft (JO 844/1-1) and the Lendület Program of the Hungarian Academy of Sciences (LP2012-43). The work of Z.P. is supported by the Hungarian Scientific Research Fund (OTKA K 100687). P.S-C. has a research grant from the Spanish ”Ministerio de Economía y Competitividad” (PI012/0097). P.N. and M.L-T. have a grant from Ministerio de Economía y Competitividad (SAF 2012-38636) and supported in part by a research grant awarded by SENEFRO Foundation.

\section{Footnotes}

\begin{abstract}
${ }^{1}$ Abbreviations
aHUS, atypical hemolytic uremic syndrome; BSA, bovine serum albumin; C3Nef, C3 nephritic factor; C4Nef, C4 nephritic factor; CFHR, complement factor H-related; DDD, dense deposit disease; MPGN, membranoproliferative glomerulonephritis; NHP, normal human plasma; SCR, short consensus repeat
\end{abstract}




\section{References}

[1] Ricklin D, Hajishengallis G, Yang K, Lambris JD. Complement: a key system for immune surveillance and homeostasis. Nat Immunol 2010;11:785-97.

[2] Sjöberg AP, Trouw LA, Blom AM. Complement activation and inhibition: a delicate balance. Trends Immunol 2009;30:83-90.

[3] Ricklin D, Lambris JD. Complement in immune and inflammatory disorders: pathophysiological mechanisms. J Immunol 2013;190:3831-8.

[4] Dragon-Durey MA, Blanc C, Marinozzi MC, van Schaarenburg RA, Trouw LA. Autoantibodies against complement components and functional consequences. Mol Immunol 2013;56:213-21.

[5] Pickering MC, Cook HT. Translational mini-review series on complement factor H: renal diseases associated with complement factor $\mathrm{H}$ : novel insights from humans and animals. Clin Exp Immunol 2008;151:210-30.

[6] Skerka C, Licht C, Mengel M, Uzonyi B, Strobel S, Zipfel PF et al. Autoimmune forms of thrombotic microangiopathy and membranoproliferative glomerulonephritis: Indications for a disease spectrum and common pathogenic principles. Mol Immunol 2009;46:2801-7.

[7] Servais A, Noël LH, Roumenina LT, Le Quintrec M, Ngo S, Dragon-Durey MA et al. Acquired and genetic complement abnormalities play a critical role in dense deposit disease and other C3 glomerulopathies. Kidney Int 2012;82:454-64.

[8] Pickering MC, D'Agati VD, Nester CM, Smith RJ, Haas M, Appel GB et al. C3 glomerulopathy: consensus report. Kidney Int 2013;84:1079-89. 
[9] Strife CF, Leahy AE, West CD. Antibody to a cryptic, solid phase C1Q antigen in membranoproliferative nephritis. Kidney Int 1989;35:836-42.

[10] Strife CF, Prada AL, Clardy CW, Jackson E, Forristal J. Autoantibody to complement neoantigens in membranoproliferative glomerulonephritis. J Pediatr 1990;116:S98102.

[11] Strobel S, Zimmering M, Papp K, Prechl J, Józsi M. Anti-factor B autoantibody in dense deposit disease. Mol Immunol 2010;47:1476-83.

[12] Spitzer RE, Vallota EH, Forristal J, Sudora E, Stitzel A, Davis NC et al. Serum C'3 lytic system in patients with glomerulonephritis. Science 1969;164:436-7.

[13] Spitzer RE, Stitzel AE, Tsokos GC. Production of IgG and IgM autoantibody to the alternative pathway C3 convertase in normal individuals and patients with membranoproliferative glomerulonephritis. Clin Immunol Immunopathol 1990;57:108.

[14] Daha MR, Van Es LA. Stabilization of homologous and heterologous cell-bound amplification convertases, C3bBb, by C3 nephritic factor. Immunology 1981;43:33-8.

[15] Clardy CW, Forristal J, Strife CF, West CD. A properdin dependent nephritic factor slowly activating C3, C5, and C9 in membranoproliferative glomerulonephritis, types I and III. Clin Immunol Immunopathol 1989;50:333-47.

[16] Tanuma Y, Ohi H, Hatano M. Two types of C3 nephritic factor: properdin-dependent $\mathrm{C} 3 \mathrm{NeF}$ and properdin-independent C3NeF. Clin Immunol Immunopathol 1990;56:226-38.

[17] Daha MR, Fearon DT, Austen KF. C3 nephritic factor (C3NeF): stabilization of fluid phase and cell-bound alternative pathway convertase. J Immunol 1976;116:1-7. 
[18] Weiler JM, Daha MR, Austen KF, Fearon DT. Control of the amplification convertase of complement by the plasma protein beta1H. Proc Natl Acad Sci U S A 1976;73:3268-72.

[19] Ito S, Tamura N, Fujita T. Effect of decay-accelerating factor on the assembly of the classical and alternative pathway C3 convertases in the presence of C4 or C3 nephritic factor. Immunology 1989;68:449-52.

[20] Daha MR, Kok DJ, Van Es LA. Regulation of the C3 nephritic factor stabilized C3/C5 convertase of complement by purified human erythrocyte C3b receptor. Clin Exp Immunol 1982;50:209-14.

[21] Ohi H, Watanabe S, Fujita T, Yasugi T. Significance of C3 nephritic factor (C3NeF) in non-hypocomplementaemic serum with membranoproliferative glomerulonephritis (MPGN). Clin Exp Immunol 1992;89:479-84.

[22] Paixão-Cavalcante D, López-Trascasa M, Skattum L, Giclas PC, Goodship TH, Rodrígez de Córdoba S et al. Sensitive and specific assays for C3 nephritic factors clarify mechanisms underlying complement dysregulation. Kidney Int 2012;82:108492.

[23] Mollnes TE, Ng YC, Peters DK, Lea T, Tschopp J, Harboe M. Effect of nephritic factor on C3 and on the terminal pathway of complement in vivo and in vitro. Clin Exp Immunol 1986;65:73-9.

[24] Smith RJ, Alexander J, Barlow PN, Botto M, Cassavant TL, Cook HT, et al. New approaches to the treatment of dense deposit disease. J Am Soc Nephrol 2007;18:2447-56.

[25] Schwertz R, Rother U, Anders D, Gretz N, Schärer K, Kirschfink M. Complement analysis in children with idiopathic membranoproliferative glomerulonephritis: a long-term follow-up. Pediatr Allergy Immunol 2001;12:166-72. 
[26] Appel GB, Cook HT, Hageman G, Jennette JC, Kashgarian M, Kirschfink M et al. Membranoproliferative glomerulonephritis type II (dense deposit disease): an update. J Am Soc Nephrol 2005;16:1392-403.

[27] Servais A, Frémeaux-Bacchi V, Lequintrec M, Salomon R, Blouin J, Knebelmann B et al. Primary glomerulonephritis with isolated C3 deposits: a new entity which shares common genetic risk factors with haemolytic uraemic syndrome. J Med Genet 2007;44:193-9.

[28] Mathieson PW, Würzner R, Oliveria DB, Lachmann PJ, Peters DK. Complementmediated adipocyte lysis by nephritic factor sera. J Exp Med 1993;177:1827-31.

[29] Sissons JG, West RJ, Fallows J, Williams DG, Boucher BJ, Amos N et al. The complement abnormalities of lipodystrophy. N Engl J Med 1976;294:461-5.

[30] Walport MJ, Davies KA, Botto M, Naughton MA, Isenberg DA, Biasi D et al. C3 nephritic factor and SLE: report of four cases and review of the literature. Q J Med 1994;87:609-15.

[31] Spitzer RE, Stitzel AE, Tsokos GC. Evidence that production of autoantibody to the alternative pathway C3 convertase is a normal physiologic event. J Pediatr 1990;116:S103-8.

[32] Spitzer RE, Stitzel AE, Tsokos G. On the origin of C3 nephritic factor (antibody to the alternative pathway C3 convertase): evidence for the Adam and Eve concept of autoantibody production. Clin Immunol Immunopathol 1992;64:177-83.

[33] López-Trascasa M, Marín MA, Fontán G. C3 nephritic factor determination. A comparison between two methods. J Immunol Methods 1987;98:77-82.

[34] Rother U. A new screening test for C3 nephritis factor based on a stable cell bound convertase on sheep erythrocytes. J Immunol Methods 1982;51:101-7. 
[35] West CD. A hemolytic method for the measurement of nephritic factor. J Immunol Methods 2008;335:1-7.

[36] Seino J, Fukuda K, Kinoshita Y, Sudo K, Horigome I, Sato H et al. Quantitation of C3 nephritic factor of alternative complement pathway by an enzyme-linked immunosorbent assay. J Immunol Methods 1987;105:119-25.

[37] Zhang Y, Meyer NC, Wang K, Nishimura C, Frees K, Jones M et al. Causes of alternative pathway dysregulation in dense deposit disease. Clin J Am Soc Nephrol 2012;7:265-74.

[38] Tanuma Y, Ohi H, Watanabe S, Seki M, Hatano M. C3 nephritic factor and C4 nephritic factor in the serum of two patients with hypocomplementaemic membranoproliferative glomerulonephritis. Clin Exp Immunol 1989;76:82-5.

[39] Ohi H, Yasugi T. Occurrence of C3 nephritic factor and C4 nephritic factor in membranoproliferative glomerulonephritis (MPGN). Clin Exp Immunol 1994;95:31621.

[40] Leroy V, Fremeaux-Bacchi V, Peuchmaur M, Baudouin V, Deschênes G, Macher MA, Loirat C. Membranoproliferative glomerulonephritis with $\mathrm{C} 3 \mathrm{NeF}$ and genetic complement dysregulation. Pediatr Nephrol 2011;26:419-24.

[41] West CD, Witte DP, McAdams AJ. Composition of nephritic factor-generated glomerular deposits in membranoproliferative glomerulonephritis type 2. Am J Kidney Dis 2001;37:1120-30.

[42] Halbwachs L, Leveillé M, Lesavre P, Wattel S, Leibowitch J. Nephritic factor of the classical pathway of complement: immunoglobulin G autoantibody directed against the classical pathway C3 convetase enzyme. J Clin Invest 1980;65:1249-56.

[43] Daha MR, van Es LA. Relative resistance of the F-42-stabilized classical pathway C3 convertase to inactivation by C4-binding protein. J Immunol 1980;125:2051-4. 
[44] Gigli I, Sorvillo J, Mecarelli-Halbwachs L, Leibowitch J. Mechanism of action of the C4 nephritic factor. Deregulation of the classical pathway of C3 convertase. J Exp Med 1981;154:1-12.

[45] Fischer E, Kazatchkine MD, Mecarelli-Halbwachs L. Protection of the classical and alternative complement pathway C3 convertases, stabilized by nephritic factors, from decay by the human C3b receptor. Eur J Immunol 1984;14:1111-4.

[46] Fujita T, Sumita T, Yoshida S, Ito S, Tamura N. C4 nephritic factor in a patient with chronic glomerulonephritis. J Clin Lab Immunol 1987;22:65-70.

[47] Seino J, Kinoshita Y, Sudo K, Horigome I, Sato H, Narita M et al. Quantitation of C4 nephritic factor by an enzyme-linked immunosorbent assay. Immunol Methods 1990;128:101-8.

[48] Chen Q, Müller D, Rudolph B, Hartmann A, Kuwertz-Bröking E, Wu K et al. Combined C3b and factor B autoantibodies and MPGN type II. N Engl J Med 2011;365:2340-2.

[49] Meri S, Koistinen V, Miettinen A, Törnroth T, Seppälä IJ. Activation of the alternative pathway of complement by monoclonal lambda light chains in membranoproliferative glomerulonephritis. J Exp Med 1992;175:939-50.

[50] Jokiranta TS, Solomon A, Pangburn MK, Zipfel PF, Meri S. Nephritogenic lambda light chain dimer: a unique human miniautoantibody against complement factor $\mathrm{H}$. $\mathrm{J}$ Immunol 1999;163:4590-6.

[51] Nozal P, Strobel S, Ibernon M, López D, Sánchez-Corral P, Rodríguez de Córdoba S et al. Anti-factor $\mathrm{H}$ antibody affecting factor $\mathrm{H}$ cofactor activity in a patient with dense deposit disease. Clin Kidney J 2012;5:133-6. 
[52] Goodship TH, Pappworth IY, Toth T, Denton M, Houlberg K, McCormick F et al. Factor $\mathrm{H}$ autoantibodies in membranoproliferative glomerulonephritis. Mol Immunol 2012;52:200-6.

[53] Sethi S, Fervenza FC, Zhang Y, Nasr SH, Leung N, Vrana J et al. Proliferative glomerulonephritis secondary to dysfunction of the alternative pathway of complement. Clin J Am Soc Nephrol 2011;6:1009-17.

[54] Zand L, Kattah A, Fervenza FC, Smith RJ, Nasr SH, Zhang Y et al. C3 glomerulonephritis associated with monoclonal gammopathy: a case series. Am J Kidney Dis 2013;62:506-14.

[55] Kavanagh D, Goodship TH, Richards A. Atypical hemolytic uremic syndrome. Semin Nephrol 2013;33:508-30.

[56] Józsi M, Zipfel PF. Factor H family proteins and human diseases. Trends Immunol 2008;29:380-7.

[57] Dragon-Durey MA, Loirat C, Cloarec S, Macher MA, Blouin J, Nivet H et al. AntiFactor $\mathrm{H}$ autoantibodies associated with atypical hemolytic uremic syndrome. J Am Soc Nephrol 2005;16:555-63.

[58] Kavanagh D, Pappworth IY, Anderson H, Hayes CM, Moore I, Hunze EM et al. Factor I autoantibodies in patients with atypical hemolytic uremic syndrome: diseaseassociated or an epiphenomenon? Clin J Am Soc Nephrol 2012;7:417-26.

[59] Watson R, Lindner S, Bordereau P, Hunze EM, Tak F, Ngo S et al. Standardisation of the factor H autoantibody assay. Immunobiology 2014;219:9-16.

[60] Dragon-Durey MA, Blanc C, Roumenina LT, Poulain N, Ngo S, Bordereau P, Frémeaux-Bacchi V. Anti-factor h autoantibodies assay. Methods Mol Biol 2014;1100:249-56. 
[61] Józsi M. Anti-Factor H Autoantibodies in Kidney Disease: Detection, Pathogenic Role, and Relevance for Treatment. In: Jenkins GE, Hall JI, editors. Autoantibodies: Detection, Pathogenicity and Health Implications, Hauppauge: Nova Science Publishers; 2012, p. 37-57.

[62] Strobel S, Abarrategui-Garrido C, Fariza-Requejo E, Seeberger H, Sánchez-Corral P, Józsi M. Factor H-related protein 1 neutralizes anti-factor $\mathrm{H}$ autoantibodies in autoimmune hemolytic uremic syndrome. Kidney Int 2011;80:397-404.

[63] Strobel S, Hoyer PF, Mache CJ, Sulyok E, Liu WS, Richter H et al. Functional analyses indicate a pathogenic role of factor $\mathrm{H}$ autoantibodies in atypical haemolytic uraemic syndrome. Nephrol Dial Transplant 2010;25:136-44.

[64] Dragon-Durey MA, Sethi SK, Bagga A, Blanc C, Blouin J, Ranchin B et al. Clinical features of anti-factor $\mathrm{H}$ autoantibody-associated hemolytic uremic syndrome. J Am Soc Nephrol 2010;21:2180-7.

[65] Blanc C, Roumenina LT, Ashraf Y, Hyvärinen S, Sethi SK, Ranchin B et al. Overall neutralization of complement factor $\mathrm{H}$ by autoantibodies in the acute phase of the autoimmune form of atypical hemolytic uremic syndrome. $\mathrm{J}$ Immunol 2012;189:3528-37.

[66] Nozal P, Garrido S, Alba-Domínguez M, Espinosa L, Peña A, Rodríguez de Córdoba S et al. An ELISA assay with two monoclonal antibodies allows the estimation of free Factor $\mathrm{H}$ and identifies patients with acquired deficiency of this complement regulator. Mol Immunol 2013;58:194-200.

[67] Sinha A, Gulati A, Saini S, Blanc C, Gupta A, Gurjar BS et al. Prompt plasma exchanges and immunosuppressive treatment improves the outcomes of anti-factor $\mathrm{H}$ autoantibody-associated hemolytic uremic syndrome in children. Kidney Int 2013 Oct 2. doi: 10.1038/ki.2013.373. 
[68] Józsi M, Licht C, Strobel S, Zipfel SL, Richter H, Heinen S et al. Factor H autoantibodies in atypical hemolytic uremic syndrome correlate with CFHR1/CFHR3 deficiency. Blood 2008;111:1512-4.

[69] Moore I, Strain L, Pappworth I, Kavanagh D, Barlow PN, Herbert AP et al. Association of factor $\mathrm{H}$ autoantibodies with deletions of CFHR1, CFHR3, CFHR4, and with mutations in $\mathrm{CFH}$, CFI, CD46, and C3 in patients with atypical hemolytic uremic syndrome. Blood 2010;115:379-87.

[70] Hofer J, Janecke AR, Zimmerhackl LB, Riedl M, Rosales A, Giner $\mathrm{T}$ et al. Complement factor H-related protein 1 deficiency and factor $\mathrm{H}$ antibodies in pediatric patients with atypical hemolytic uremic syndrome. Clin J Am Soc Nephrol 2013;8:407-15.

[71] Dragon-Durey MA, Blanc C, Marliot F, Loirat C, Blouin J, Sautes-Fridman C et al. The high frequency of complement factor $\mathrm{H}$ related CFHR1 gene deletion is restricted to specific subgroups of patients with atypical haemolytic uraemic syndrome. J Med Genet 2009;46:447-50.

[72] Abarrategui-Garrido C, Martínez-Barricarte R, López-Trascasa M, de Córdoba SR, Sánchez-Corral P. Characterization of complement factor H-related (CFHR) proteins in plasma reveals novel genetic variations of CFHR1 associated with atypical hemolytic uremic syndrome. Blood 2009;114:4261-71.

[73] Józsi M, Strobel S, Dahse HM, Liu WS, Hoyer PF, Oppermann M et al. Anti factor H autoantibodies block C-terminal recognition function of factor $\mathrm{H}$ in hemolytic uremic syndrome. Blood 2007;110:1516-8.

[74] Kopp A, Strobel S, Tortajada A, Rodríguez de Córdoba S, Sánchez-Corral P, Prohászka Z et al. Atypical hemolytic uremic syndrome-associated variants and 
autoantibodies impair binding of factor $\mathrm{h}$ and factor h-related protein 1 to pentraxin 3. J Immunol 2012;189:1858-67.

[75] Boyer O, Balzamo E, Charbit M, Biebuyck-Gougé N, Salomon R, Dragon-Durey MA et al. Pulse cyclophosphamide therapy and clinical remission in atypical hemolytic uremic syndrome with anti-complement factor $\mathrm{H}$ autoantibodies. Am J Kidney Dis 2010;55:923-7.

[76] Kim JJ, McCulloch M, Marks SD, Waters A, Noone D. The clinical spectrum of hemolytic uremic syndrome secondary to complement factor $\mathrm{H}$ autoantibodies. Clin Nephrol 2013 Oct 16. [Epub ahead of print] DOI 10.5414/CN107777

[77] Sana G, Dragon-Durey MA, Charbit M, Bouchireb K, Rousset-Rouvière C, Bérard E, Salomon R, Frémeaux-Bacchi V, Niaudet P, Boyer O. Long-term remission of atypical HUS with anti-factor $\mathrm{H}$ antibodies after cyclophosphamide pulses. Pediatr Nephrol 2014 Jan;29:75-83.

[78] Kwon T, Dragon-Durey MA, Macher MA, Baudouin V, Maisin A, Peuchmaur M et al. Successful pre-transplant management of a patient with anti-factor $\mathrm{H}$ autoantibodies-associated haemolytic uraemic syndrome. Nephrol Dial Transplant 2008;23:2088-90.

[79] Le Quintrec M, Zuber J, Noel LH, Thervet E, Frémeaux-Bacchi V, Niaudet P et al. Anti-Factor $\mathrm{H}$ autoantibodies in a fifth renal transplant recipient with atypical hemolytic and uremic syndrome. Am J Transplant 2009;9:1223-9.

[80] Legendre CM, Licht C, Muus P, Greenbaum LA, Babu S, Bedrosian C et al. Terminal complement inhibitor eculizumab in atypical hemolytic-uremic syndrome. N Engl J Med 2013;368:2169-81. 
[81] McCaughan JA, O'Rourke DM, Courtney AE. Recurrent dense deposit disease after renal transplantation: an emerging role for complementary therapies. Am J Transplant 2012;12:1046-51.

[82] Daina E, Noris M, Remuzzi G. Eculizumab in a patient with dense-deposit disease. N Engl J Med 2012;366:1161-3.

[83] Vivarelli M, Pasini A, Emma F. Eculizumab for the treatment of dense-deposit disease. N Engl J Med 2012;366:1163-5.

[84] Bomback AS, Smith RJ, Barile GR, Zhang Y, Heher EC, Herlitz L et al. Eculizumab for dense deposit disease and C3 glomerulonephritis. Clin J Am Soc Nephrol 2012;7:748-56.

[85] Noone D, Waters A, Pluthero FG, Geary DF, Kirschfink M, Zipfel PF, Licht C. Successful treatment of DEAP-HUS with eculizumab. Pediatr Nephrol 2013 Nov 20. [Epub ahead of print] DOI 10.1007/s00467-013-2654-x

[86] Wong EK, Goodship TH, Kavanagh D. Complement therapy in atypical haemolytic uraemic syndrome (aHUS). Mol Immunol 2013;56:199-212.

[87] Schmidt CQ, Slingsby FC, Richards A, Barlow PN. Production of biologically active complement factor $\mathrm{H}$ in therapeutically useful quantities. Protein Expr Purif 2011;76:254-63.

[88] Schmidt CQ, Bai H, Lin Z, Risitano AM, Barlow PN, Ricklin D, Lambris JD. Rational engineering of a minimized immune inhibitor with unique triple-targeting properties. J Immunol 2013;190:5712-21.

[89] Hebecker M, Alba-Domínguez M, Roumenina LT, Reuter S, Hyvärinen S, DragonDurey MA et al. An engineered construct combining complement regulatory and surface-recognition domains represents a minimal-size functional factor H. J Immunol 2013;191:912-21. 


\section{Figure legends}

Fig. 1. Schematic view of complement activation. The complement system can be activated through three major pathways. The classical and lectin pathways lead to the generation of the C3 convertase enzyme C4bC2b that cleaves C3 into C3a and C3b. Similarly, alternative pathway activation leads to the generation of the $\mathrm{C} 3$ convertase enzyme $\mathrm{C} 3 \mathrm{bBb}$ that cleaves C3. In addition, C3b generated by any pathway feeds into the alternative pathway by forming $\mathrm{C} 3 \mathrm{bBb}$ enzymes. When $\mathrm{C} 3 \mathrm{~b}$ deposits to either $\mathrm{C} 4 \mathrm{bC} 2 \mathrm{~b}$ or $\mathrm{C} 3 \mathrm{bBb}$, the enzymes gain the ability to cleave C5 into C5a and C5b, the latter initiating the terminal complement pathway that may eventually lead to the formation of terminal complement complexes and allow lysis of target cells. The activation of complement is regulated by several soluble and membranebound molecules. The figure shows those regulators to which autoantibodies in C3 glomerulopathy and aHUS have been described. The antibodies target the C3 convertase or its components (C3b and factor $\mathrm{B}$ ), its negative regulators (factor $\mathrm{H}$ and factor $\mathrm{I}$ ), or the positive regulator properdin.

Fig. 2. Specificity of a DDD-associated factor B autoantibody. An ELISA was used to analyze the binding of IgGs from sera (diluted 1:100) of a DDD patient with factor B autoantibodies (black bars), an aHUS patient with factor $\mathrm{H}$ autoantibodies (dotted bars), or a healthy control (white bars), to the C3 convertase components factor B (FB) and C3b, and to the regulators properdin (FP) and factor $\mathrm{H}(\mathrm{FH})$, which were immobilized at $5 \mu \mathrm{g} / \mathrm{ml}$. Bovine serum albumin (BSA) was used as control of unspecific binding. Data are mean + SD of three experiments.

Fig. 3. Western blot analysis of a dense deposit disease-associated factor $\mathbf{H}$ autoantibody. (A) Serum IgG fractions were isolated from an anti-factor $\mathrm{H}$ positive patient with DDD (lane 1), a patient with aHUS and factor $\mathrm{H}$ autoantibodies (lane 2), and a healthy donor (lane 3). 10 
$\mu \mathrm{g}$ of the IgG fractions was separated on 10\% SDS-PAGE and transferred to nitrocellulose membrane. In lane 4, $1 \mu \mathrm{l}$ normal human plasma (NHP) was run as a control. The membrane was developed using a monoclonal antibody recognizing domain 1 of factor $\mathrm{H}$ and factor $\mathrm{H}$ like protein 1 (CFHL1). The IgG fractions of the patients (lanes 1 and 2) contained both free autoantibodies and immune complexes. (B) The schematic drawing shows the 20 factor $\mathrm{H}$ domains and the domains of CFHL1, which is generated from the $C F H$ gene by alternative splicing. CFHL1 contains the $7 \mathrm{~N}$-terminal domains of factor $\mathrm{H}$, including the four domains responsible for complement regulation (shown in grey), and four C-terminal amino acids, not present in factor H. Thus, CFHL1 and factor $\mathrm{H}$ share complement regulatory activity.

Fig. 4. Characterization of aHUS-associated factor I autoantibodies by ELISA. (A) Serum immunoglobulins from two aHUS patients bind to immobilized factor I ( $5 \mu \mathrm{g} / \mathrm{ml})$ in a dose-dependent manner. Three control sera are shown for comparison. Data of a representative experiement are shown. (B) Binding to immobilized factor I before and after IgG-depletion by incubation with protein G (sera diluted 1:100). Data are mean + SD of three experiments. (C) Dose-dependent binding of purified IgG from patient 1 to immobilized factor I; no binding is observed with a control IgG. Data are mean + SD of three experiments. (D) The binding of autoantibodies from the serum of patient 1 (diluted 1:100) to immobilized factor I was inhibited by adding purified factor I, whereas BSA had no inhibitory effect. Data of a representative experiement are shown.

Fig. 5. Characterization of C3b autoantibodies from an aHUS patient by ELISA. (A) IgG binding to C3, C3b, iC3b, C3d and BSA (immobilized at $5 \mu \mathrm{g} / \mathrm{ml}$ ) observed with the patient's serum and with a control serum (both diluted 1:100). (B) The patient's autoantibodies bind to immobilized C3b in a dose-dependent manner. IgG binding from a control serum is shown for comparison. (C) IgG binding to immobilized C3b before and after IgG-depletion (sera diluted 
1:100). (D) Autoantibody binding to C3b can be inhibited by adding purified C3b to the patient's plasma (diluted 1:100), whereas factor $\mathrm{H}$ had no inhibitory effect. Data represent mean + SD of three experiments. 
Figure 1

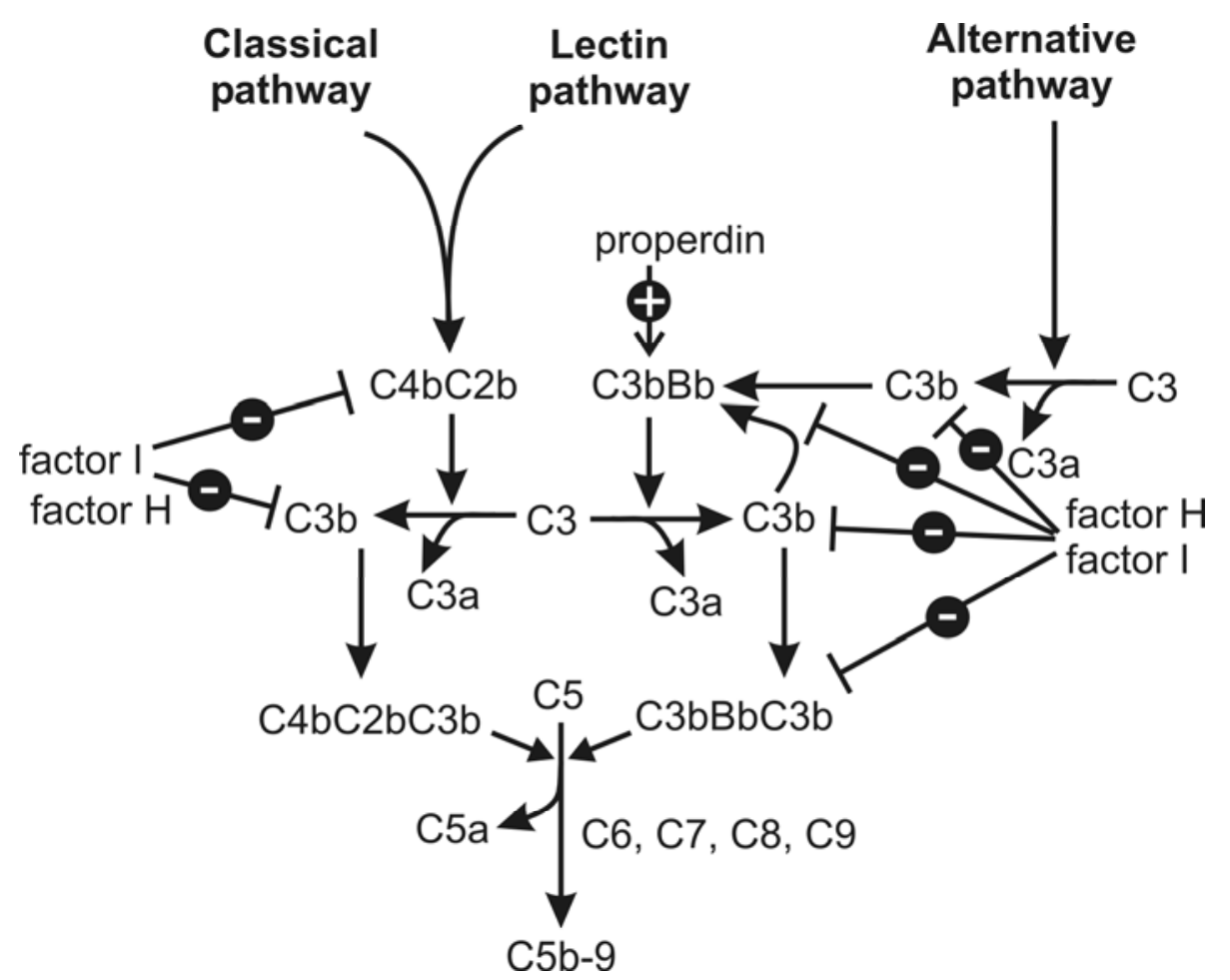

Figure 2

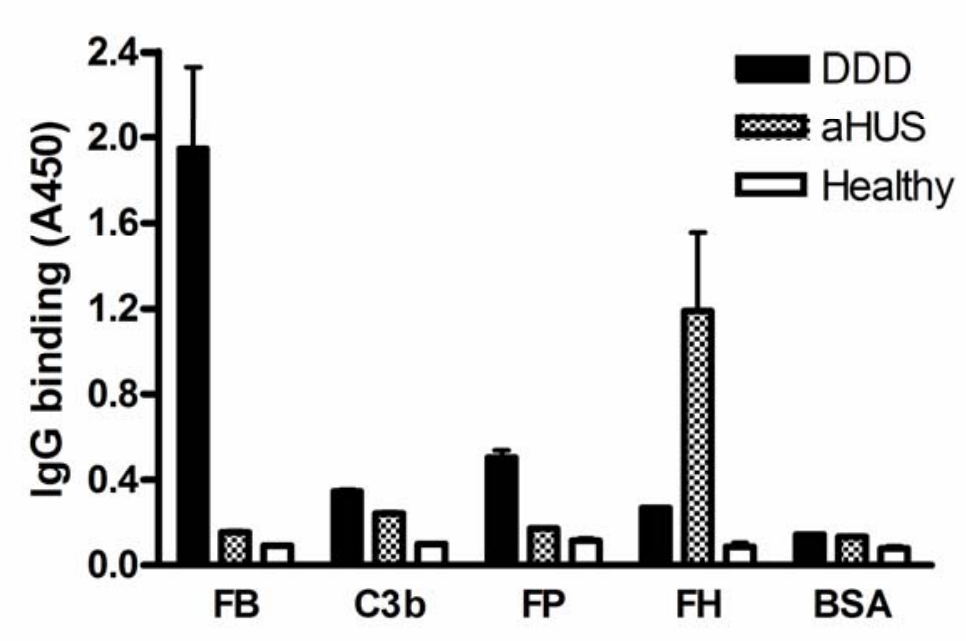


Figure 3

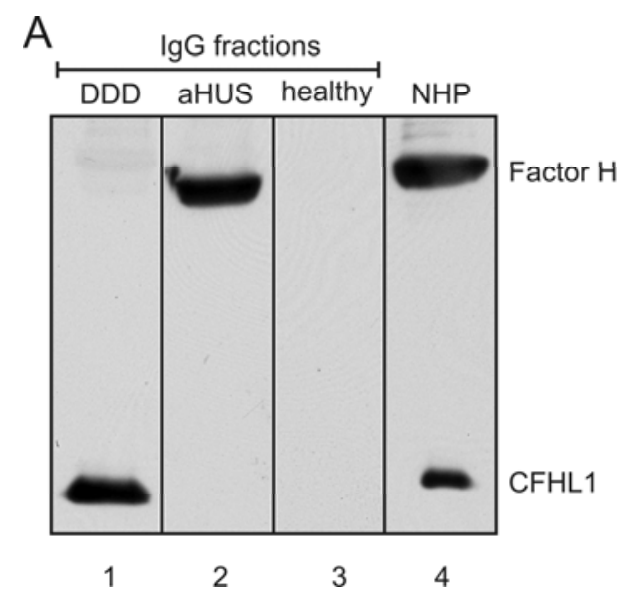

B

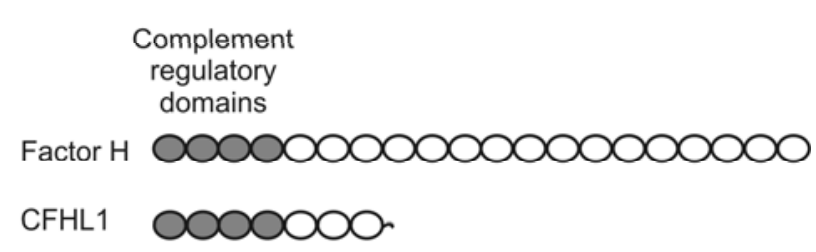

Figure 4

A

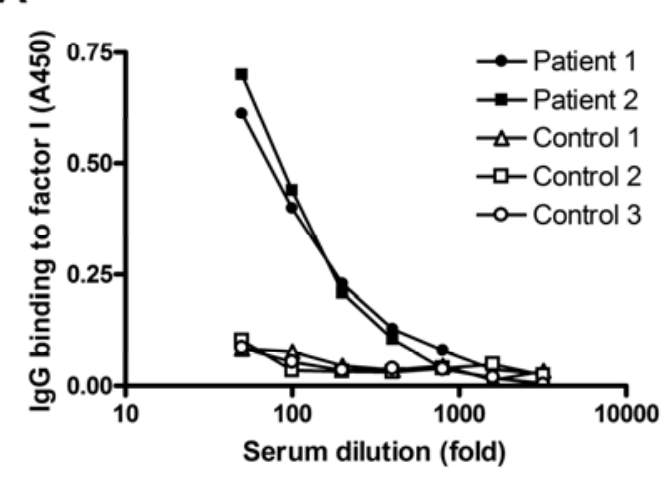

\section{C}

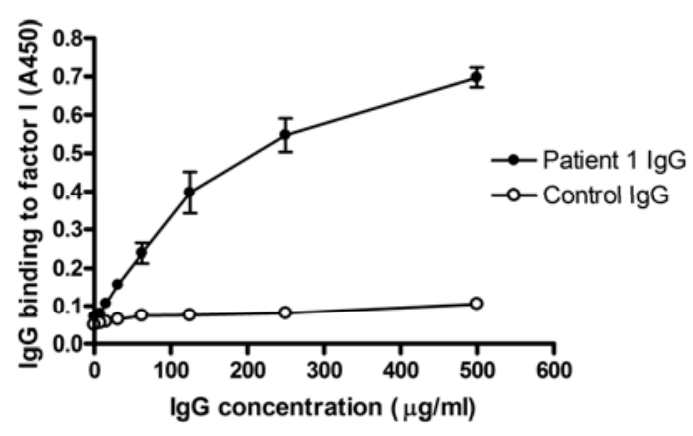

B

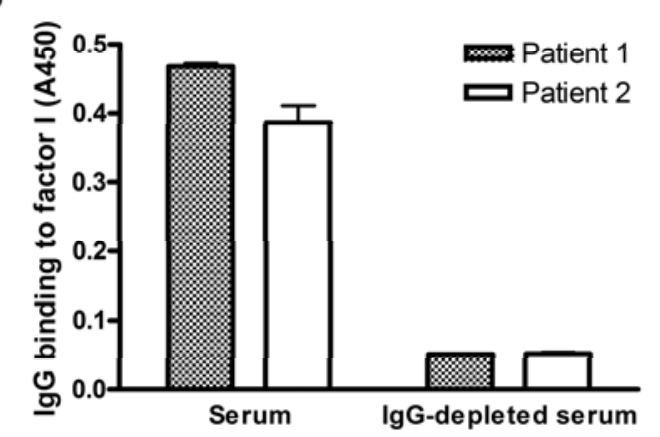

D

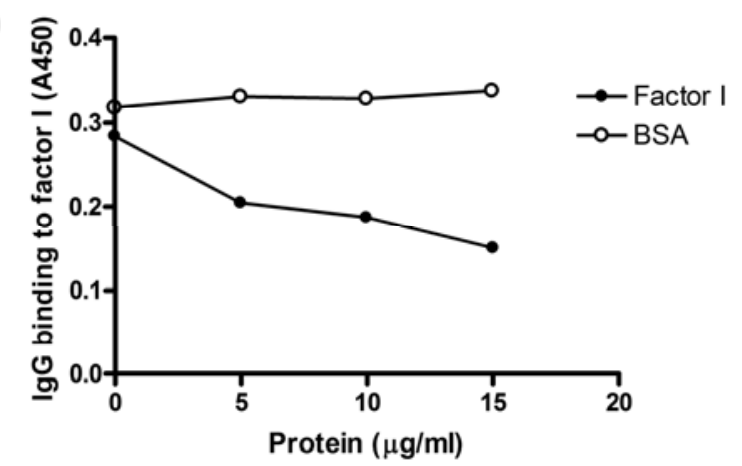


Figure 5
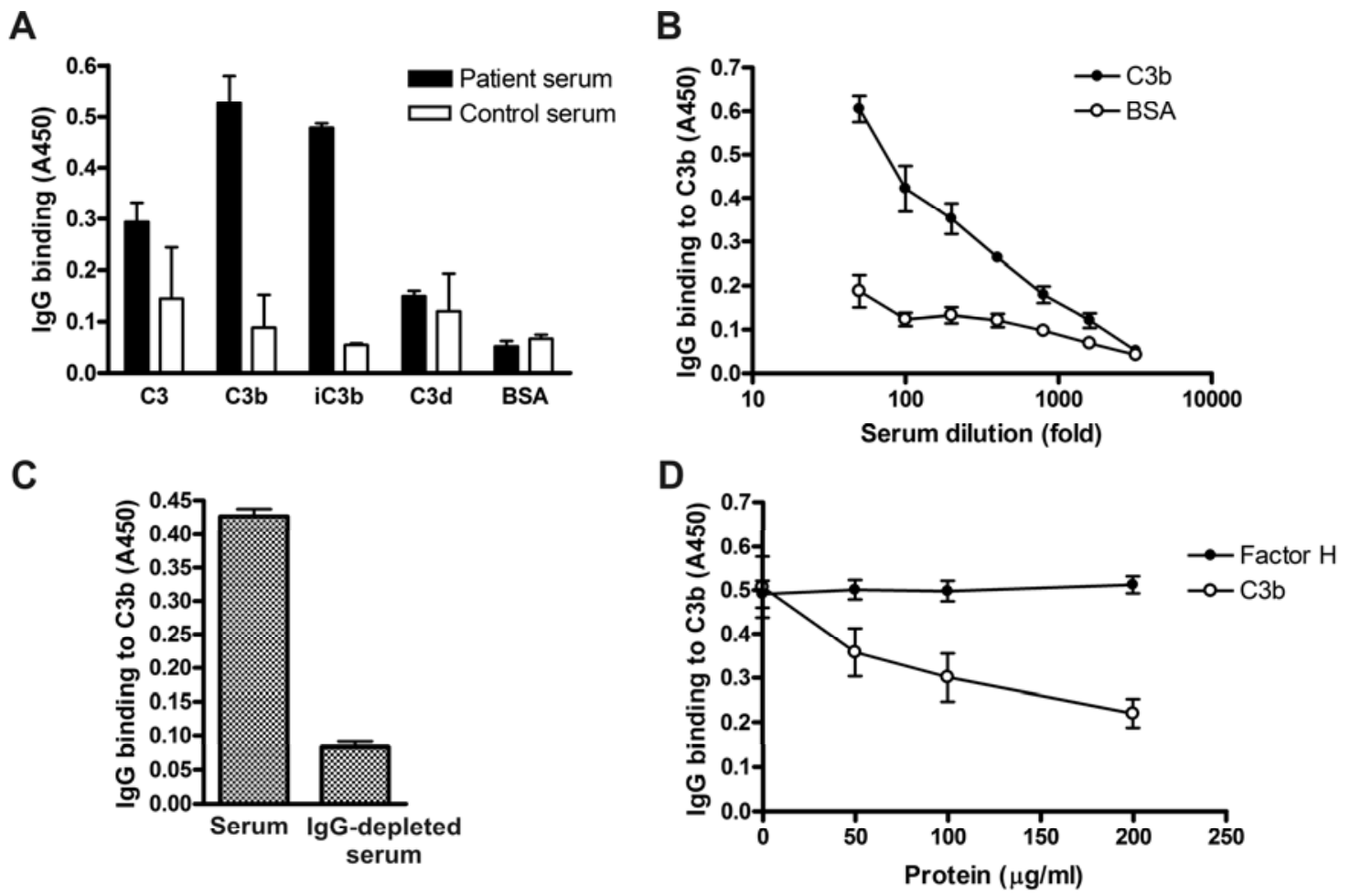